4. Jha, C. S. et al., Characterization of species diversity and forest health using AVIRIS-NG hyperspectral remote sensing data. Hyperspectral Imaging, 2019, 116, 12.

5. Ollinger, S. V., Sources of variability in canopy reflectance and the convergent properties of plants. New Phytol., 2011, 189, 375-394.

6. Hall, F. G., Shimabukuro, Y. E. and Huemmrich, K. F., Remote sensing of forest biophysical structure using mixture decomposition and geometric reflectance models. Ecol. Appl., 1995, 5, 993-1013.

7. Rautiainen, M., Stenberg, P., Nilson, T. and Kuusk, A., The effect of crown shape on the reflectance of coniferous stands. Remote Sensing Environ., 2004, 89, 41-52.

8. Funk, C. et al., The climate hazards infrared precipitation with stations - a new environmental record for monitoring extremes. Sci. Data, 2015, 2, 1-21.

9. Ustuner, M., Sanli, F. B. and Dixon, B., Application of support vector machines for landuse classification using high-resolution rapid eye images: a sensitivity analysis. Eur. J. Remote Sensing, 2015, 48, 403-422.

ACKNOWLEDGEMENTS. We thank DST-NISA (BDID/01/23/ 2014-HSRS/20) and SAC-ISRO-AVIRIS-NG-AO for financial assistance. We also thank Dr Bimal Bhattacharya (SAC-ISRO, Ahmedabad, India) for support, and Philip Townsend, Adam Chlus and Zhiwei Ye (University of Wisconsin, USA) for sharing topographic and BRDFcorrected AVIRIS-NG images for the four forest covers.

\section{Effective use of synthetic seed technology in the regeneration of Cymbidium aloifolium using protocorm-like bodies}

\author{
Shivani Verma* and Promila Pathak \\ Orchid Laboratory, Botany Department, Panjab University, \\ Chandigarh 160014 , India
}

Synthetic seed technology offers tremendous potential in micropropagation. It deals with in vitro conservation and storage of rare and endangered plant species along with their easy handling and transportation. This technology is becoming prevelant due to its wide applications in germplasm conservation and for exchanges between countries in floricultural trade. The present study examines the regeneration and conversion capabilities of Cymbidium aloifolium using protocorm-like bodies when stored at different temperatures. The propagules showed high proliferative potential by multiplication and complete plantlets were obtained in 58 days on basal $M$ medium supplemented with $1 \mathrm{mg} \mathrm{l}^{-1}$ of indole-3-acetic acid.

Keywords: Cymbidium aloifolium, protocorm-like bodies, regeneration, synthetic seeds.

\footnotetext{
*For correspondence. (e-mail: shiv.ni.verma@gmail.com)
}

THE development of an artificial seed technique provides a good approach for enhancement of various plant species such as trees and crops ${ }^{1}$. It represents a unique system for exploiting the inherent polyembryonate potential of orchids as well ${ }^{2,3}$. This method is advantageous as it combines clonal propagation and seed propagation with the possibility of long-term storage of seeds through encapsulation in a gel-like matrix ${ }^{4}$. In this technique, non-embryogenic vegetative propagules such as shoot tips, nodal segments or axillary buds, protocorm-like bodies (PLBs) or calluses are artificially encapsulated using sodium alginate as the preferred coating agent. According to Sharma et al. ${ }^{5}$, these synthetic hydrated seeds contain nutrients that will help in the survival and speedy growth of embryos into plantlets during their cultivation after storage. This cost-effective method has proven to be quite productive, specifically for a number of orchid species ${ }^{6-14}$. The efficacy of synthetic seeds was successfully tested in Cymbidium aloifolium using PLBs, as they are easy to store and have the ability to divide as well as the best regeneration capacity which makes them ideal explants for regeneration and conservation in orchids. C. aloifolium is an Indo-Malayan, aloe-leaved, elegant epiphyte which has long earned the attention of herbalists for its therapeutic importance. According to Lawler ${ }^{15}$, it is incorporated as one of the components of an oil formulation to treat tumours which are both benign and malignant. It is also used to cure eye ailments, vertigo and paralysis. The genus figures among the endangered orchids, enlisted in Appendix II of CITES ${ }^{16}$, due to continuous destruction of its natural habitats, overexploitation for medicinal purposes, unauthorized trade and collection by orchid-lovers. The present study is a step forward to save the germplasm of this species using synthetic seed technology. The objective of the study is to determine the effects of different growth additives and different storage times in the regeneration of C. aloifolium.

The shoot-tip derived PLBs (measuring $0.2-0.3 \mathrm{~cm}$ in length) procured from in vitro-raised cultures were used to prepare synthetic seeds. Hence, these propagules did not require prior sterilization. The physical characteristics of the beads were controlled by the concentration of sodium alginate and calcium chloride used to form the calcium alginate gel (sodium alginate: $2-5 \%$ and Calcium chloride: $50-100 \mathrm{mM}$ ). The propagules were dispersed in the sodium alginate solution. The suspension was then added dropwise (each drop having a propagule) using a wide-mouthed pipette $(10 \mathrm{ml})$ to the magnetically stirred calcium chloride solution. The beads were complexed for 30 min with periodic swirling. The resultant synthetic seeds were thoroughly washed with sterilized distilled water and initially cultured on basal (M; Mitra et al. ${ }^{17}$ ) medium for four weeks and subjected to $30 \mathrm{~min}$ mild dehydration prior to encapsulation.

The conversion frequency of these seeds was tested using only $\mathrm{M}$ medium after definite time periods (15 days 


\section{RESEARCH COMMUNICATIONS}

Table 1. Effect of different growth additives on time taken for initiation response and plantlet formation (days) in synthetic seeds immediately after their preparation in Cymbidium aloifolium

\begin{tabular}{lccl}
\hline Additives $\left(1 \mathrm{mg} \mathrm{l}^{-1}\right)$ & $\begin{array}{c}\text { Time taken for initiation } \\
\text { response (days) }\end{array}$ & $\begin{array}{c}\text { Time taken for plantlet } \\
\text { formation (days) }\end{array}$ & \multicolumn{1}{c}{ Remarks } \\
\hline M & 25 & 45 & Protocorm-like bodies (PLBs) multiplication \\
M + IAA & 38 & 58 & Formation of plantlets with long roots \\
M + 2,4-D & 34 & 54 & - \\
M + BAP & 30 & 51 & PLBs multiplication \\
M + IAA + KN & 40 & 60 & PLBs multiplication \\
M IBA + BAP & 42 & 62 & PLBs multiplication \\
\hline
\end{tabular}

M, Mitra medium; IAA, Indole-3-acetic acid; 2,4-D, 2,4-Dichlorophenoxyacetic acid; BAP, 6-Benzylaminopurine; IBA, Indole-3-butyric acid; KN, Kinetin.
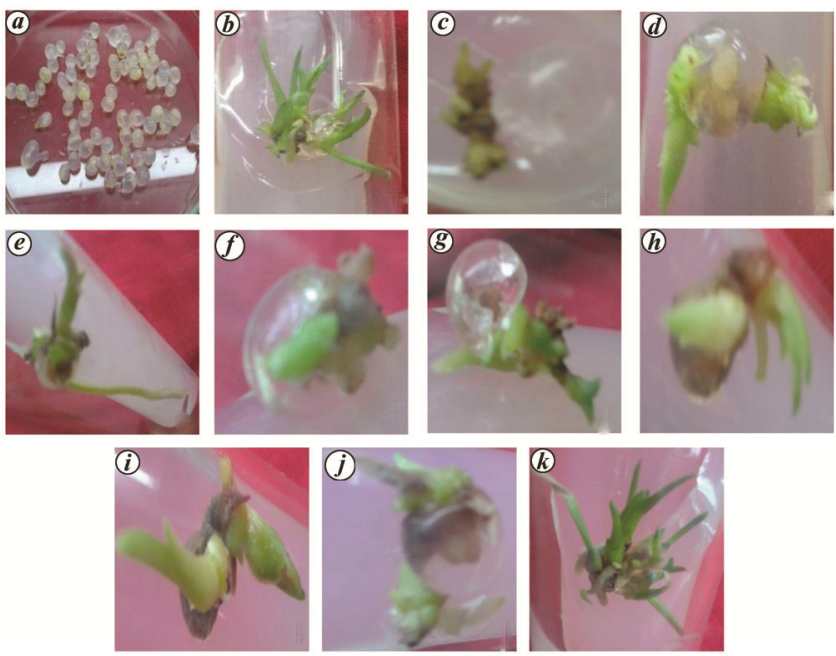

Figure 1. Synthetic seeds in Cymbidium aloifolium: a, Spherical, non-leaky and firm seeds with $3 \%$ sodium alginate and $100 \mathrm{mM}$ calcium chloride. $\boldsymbol{b}$, Multiple shoot formation $\left(\mathrm{M}+\mathrm{BAP}\left(1 \mathrm{mg} \mathrm{l}^{-1}\right)\right)$. $\boldsymbol{c}$, Formation of protocorm-like bodies (PLBs) $\left(\mathrm{M}+\mathrm{IBA}\left(1 \mathrm{mg} \mathrm{l}^{-1}\right)+\right.$ BAP $\left.\left(1 \mathrm{mg}^{-1}\right)\right)$. $\boldsymbol{d}, \boldsymbol{e}$, Formation of long roots and complete plantlet formation (M + IAA $\left.\left(1 \mathrm{mg} \mathrm{l}^{-1}\right)\right) \cdot \boldsymbol{f}, \boldsymbol{g}$, Multiplication of PLBs (M + IAA $\left.\left(1 \mathrm{mg} \mathrm{l}^{-1}\right)+\mathrm{KN}\left(1 \mathrm{mg} \mathrm{l}^{-1}\right)\right) \cdot \boldsymbol{h}, \boldsymbol{i}$, Formation of leaf primordia $(\mathrm{M}+2,4$ $\left.\mathrm{D}\left(1 \mathrm{mg} \mathrm{l}^{-1}\right)\right)$. $\boldsymbol{j}$, Multiplication of PLBs and complete plantlet formation (M). $\boldsymbol{k}$, Complete plantlet formation with well-developed roots $(\mathrm{M}+$ $\left.\operatorname{BAP}\left(1 \mathrm{mg} \mathrm{l}^{-1}\right)\right)$.

interval) to ascertain the maximum period for which the seeds could remain viable. The per cent viability of seeds was calculated by dividing the live seed count by total seed count. The seeds were stored at two different temperature regimes, viz. $4^{\circ} \mathrm{C}$ and $25^{\circ} \mathrm{C}$.

Freshly prepared seeds were inoculated on basal $\mathrm{M}$ medium with and without different plant growth regulators (PGRs) into $20 \times 150 \mathrm{~mm}$ culture tubes which were maintained at $25 \pm 2{ }^{\circ} \mathrm{C}$ under $35 \mu \mathrm{E} \mathrm{m}^{2} \mathrm{~s}^{-1}$ light intensity and $50-60 \%$ relative humidity. One set of encapsulated PLBs was kept in a refrigerator at $4^{\circ} \mathrm{C}$ and another set were kept at $25^{\circ} \mathrm{C}$. Each treatment consisted of eight replicates and observations were made by taking the average time of all replicates. The experiment was repeated twice.

In the present experiment, synthetic seeds were successfully prepared in C. aloifolium. Their physical characteristics such as size, shape and firmness varied with

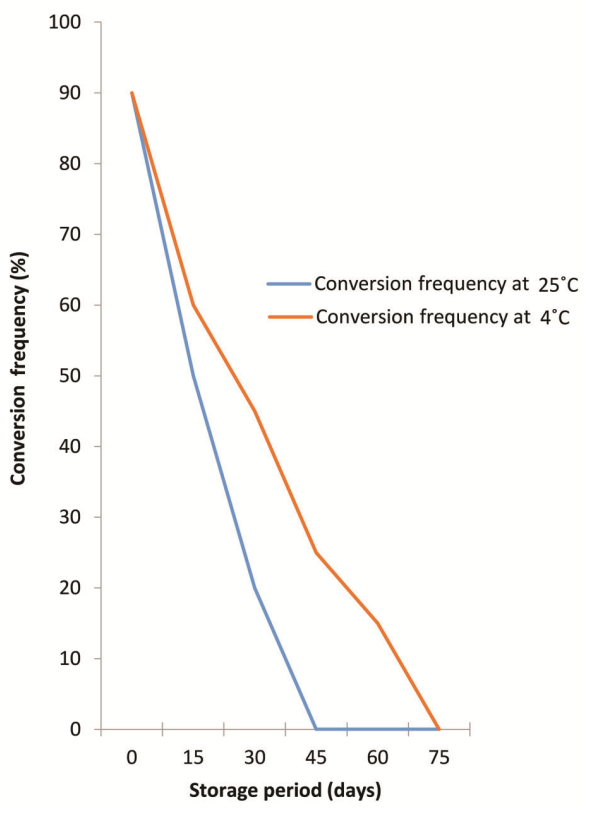

Figure 2. Effect of temperature and storage on the conversion frequency of synthetic seeds in Cymbidium aloifolium.

the concentration of the gelling agent and quantity of calcium chloride used. An encapsulation matrix of $3 \%$ sodium alginate and $100 \mathrm{mM}$ calcium chloride yielded spherical, non-leaky and firm seeds. Lower concentrations (sodium alginate; $2.0 \%, 2.5 \%$ and $\mathrm{CaCl}_{2} ; 50 \mathrm{mM}$ ) were not suitable for encapsulation as the beads formed were irregularly outlined, soft and leaky. The effect of different PGRs on the time taken for initiation response and subsequent plantlet development (days) in synthetic seeds, immediately after their preparation was analysed. Table 1 and Figure $1 a-k$ provide a summary of the results. Freshly encapsulated PLBs (i.e. control) converted with $90 \%$ frequency after 25 days, when directly inoculated on $\mathrm{M}$ medium supplemented with different growth additives. The encapsulants, i.e. PLBs multiplied and differentiated into complete plantlets in 45 days. The propagules showed high proliferative potential by their multiplication and complete plantlets were observed in 58 days on basal medium supplemented with indole-3-acetic 
acid (IAA) $\left(1 \mathrm{mg} \mathrm{l}^{-1}\right)$. However, a combination of indole3 -butyric acid (IBA) and kinetin $(\mathrm{KN})$ at $1 \mathrm{mg} \mathrm{l}^{-1}$ each resulted in delaying the initiation response and subsequent plantlet formation, which is in accordance with the results of Vij and Aggarwal ${ }^{18}$ in Vanda coerulea. According to $\mathrm{Vij}^{2}$, the exogenous requirement of plant hormones depends on their endogenous level in the plant system, which varies with the phase of plant growth.

The conversion frequency of seeds was also observed to vary with time and temperature of storage (Figure 2). The freshly prepared seeds converted readily on $\mathrm{M}$ medium and showed proliferation. Synthetic seeds stored at $4^{\circ} \mathrm{C}$ maintained their viability for a longer time compared to those stored at $25^{\circ} \mathrm{C}$ in C. aloifolium. Synthetic seeds retained $60 \%$ viability after 15 days, which gradually reduced to $45 \%$ after 30 days, $25 \%$ after 45 days and only $15 \%$ seeds converted after 60 days. However, seeds when stored at $25^{\circ} \mathrm{C}$ completely lost their viability after 45 days. Similar results were observed by Sarmah et al. ${ }^{19}$ and Pehwal et al. ${ }^{10}$ for seeds stored at $4^{\circ} \mathrm{C}$. This is possibly due to low metabolic rates at low temperatures in accordance with an earlier suggestion ${ }^{3}$. According to Sakamoto et $a .^{20}$, synthetic seeds dry quickly and are difficult to store for longer periods unless kept in humid environment and/or coated with a hydrophobic membrane, coating of substances like wax, resin, polyorganosilicane, etc. has been used by some workers ${ }^{21-23}$. However, we did not perform such experiments due to paucity of time.

Hence, if we want to store synthetic seeds for longer period, coating of substances like wax, resin, etc. should be used and then stored in refrigerators for their longer viability.

1. Hail, Z. R., Kareem, F., El-Mahrouk, M. E. and Fuller, M. P., Artificial seeds (principle, aspects and applications). Agronomy, 2017, 7, 71; doi:10.3390/agronomy7040071.

2. Vij, S. P., Regeneration response of orchid roots: a study in vitro. J. Orchid Soc. India, 1993, 7, 61-72.

3. Vij, S. P., Kher, A. and Gupta, A., Orchid micropropagation. In Biotechnology in Horticultural and Plantation Crops (eds Chadha, K. L., Ravindran, P. N. and Sahijram, L.), Malhotra Publishing House, New Delhi, 2000, pp. 598-641.

4. Lambardi, M., Benelli, C., Ozudogru, E. A. and Ozden-Tokatli, Y., Synthetic seed technology in ornamental plants. In Floriculture, Ornamental and Plant Biotechnology, Vol. II (ed. Teixeira da Silva, J. A.), Global Science Books, UK, 2006, pp. 347-354.

5. Sharma, S., Shahzad, A. and Teixeira da Silva, J. A., Synseed technology - a complete synthesis. Biotechnol. Adv., 2013, 31(2), 186-207.

6. Bektas, E., Cuce, M. and Sokmen, A., In vitro germination, protocorm formation, and plantlet development of Orchis coriophora (Orchidaceae), a naturally growing orchid species in Turkey. Turk. J. Bot., 2013, 37, 336-342.

7. Gantait, S. and Mitra, M., Applications of synthetic seed technology for propagation, storage, and conservation of orchid germplasms. In Synthetic Seeds, Springer, Cham, 2019, pp. 301321.
8. Kaur, S. and Pathak, P., Synthetic seeds and in vitro propagation of Cymbidium aloifolium (Linn.) Sw. J. Orchid Soc. India, 2014, 28, 103-108.

9. Mohanty, P., Das, M. C., Kumaria, S. and Tandon, P., Highefficiency cryopreservation of the medicinal orchid Dendrobium nobile Lindl. Plant Cell Tiss. Organ Cult., 2013, 109, 297-305.

10. Pehwal, A., Vij, S. P., Pathak, P. and Attri, L. K., Augmented shelf-life and regeneration competence of activated charcoal (AC) supplemented synthetic seeds in Cymbidium pendulum (Roxb.) Sw. Curr. Bot., 2012, 3(5), 30-34.

11. Pradhan, S., Tiruwa, B. L., Subedee, B. R. and Pant, B., Micropropagation of Cymbidium aloifolium (L.) Sw., a medicinal orchid by artificial seeds technology. J. Nat. Hist. Mus., 2014, 28, 42-48.

12. Saxena, A., Shukla, M. and Saxena, P., Synthetic seeds: relevance to endangered germplasm conservation in vitro. Synthetic Seeds, Springer, Cham, 2019, pp. 21-60.

13. Siew, W. L., Kwok, M. Y., Ong, Y. M., Liew, H. P. and Yew, B. K., Effective use of synthetic seed technology in the regeneration of Dendrobium white fairy orchid. J. Ornament. Plants, 2014, 4(1), 1-7.

14. Teixeira da Silva, J. A., Production of synseed for hybrid Cymbidium using protocorm-like bodies. J. Fruit Ornament. Plant Res., 2012, 20(2), 135-146.

15. Lawler, J., Ethnobotany of the orchidaceae - a manual In Orchid Biology, Reviews and Perspectives, Vol. III (ed. Arditti, J.), Cornell University Press, Ithaca, New York, USA, 1984, pp. 27149 .

16. CITES, Convention on International Trade in Endangered Species of Wild Fauna and Flora. Appendices I, II and III, 2014.

17. Mitra, G. C., Prasad, R. N. and Roychowdhary, A., Inorganic salts and differentiation of protocorms in seed callus of an orchid and correlated changes in its free amino acid content. Indian J. Exp. Biol., 1976, 14, 350-351.

18. Vij, S. P. and Aggarwal, S., Regeneration competence of foliar explants: Vanda coerulea Griff. J. Orchid Soc. India, 2003, 17(12), 73-78.

19. Sarmah, D. K., Borthakur, M. and Borua, P. K., Artificial seed production from encapsulated PLBs regenerated from leaf base of Vanda coerulea Griff. ex Lindl. an endangered orchid. Curr. Sci., 2010, 98, 686-690.

20. Sakamoto, Y., Onishi, N. and Hirosawa, T., Delivery system for tissue culture by encapsulation. In Automation and Environmental Control in Plant Tissue Culture (eds Aitken-Christie, J., Kozai, T. and Lila Smith, M.), Kluwer Academic Press, The Netherlands, 1995, pp. 215-243.

21. Devi, J., Ray, B. K., Chetia, S. and Deka, P. C., Regeneration of low temperature stored encapsulated protocorms of orchids. $J$. Orchid Soc. India, 1998, 12(1-2), 39-41.

22. Pathak, P., Vij, S. P. and Gautam, N., Effects of alternate gelling agents on in vitro asymbiotic germination and seedling development in Aerides multiflora Roxb.: An attempt towards developing a cost effective protocol. In Proceedings of the 18th World Orchid Conference Dijon, France Actes Proceedings, France - Orchidees, France, 2005.

23. Vij, S. P., Kaur, P. and Gupta, A., Synthetic seeds and their utility in orchids: Dendrobium densiflorum Lindl. Phytomorphology, 2001, 51, 159-165.

ACKNOWLEDGEMENT. Financial assistance from the University Grants Commission, New Delhi to S.V. is acknowledged.

Received 10 June 2020; revised accepted 4 December 2020

doi: $10.18520 / \mathrm{cs} / \mathrm{v} 120 / \mathrm{i} 3 / 570-572$ 